\title{
Colorectal polyposis and inherited colorectal cancer syndromes
}

\author{
Raphael M. Byrne, Vassiliki Liana Tsikitis \\ Oregon Health \& Science University, Portland, OR, USA
}

\begin{abstract}
The majority of colorectal cancer (CRC) cases are sporadic, with hereditary factors contributing to approximately $35 \%$ of CRC cases. Less than $5 \%$ of CRC is associated with a known genetic syndrome. Although adenomatous polyposis syndromes, hamartomatous polyposis syndromes, and those previously classified as non-polyposis CRC syndromes are quite rare, it is important for clinicians to know the characteristics of each syndrome and to understand the differences in cancer risks between the different conditions. This information is very important when treatment and surveillance plans are formulated for each individual patient.
\end{abstract}

Keywords Adenomatous polyposis syndromes, hamartomatous polyposis syndromes, nonpolyposis colorectal cancer syndromes, colorectal cancer, cancer risk

Ann Gastroenterol 2018; 31 (1): 1-11

\section{Introduction}

Most colorectal cancer (CRC) cases are sporadic, with hereditary factors contributing to approximately $35 \%$ of CRC cases [1]. Less than $5 \%$ of CRC is associated with a known genetic syndrome [2]. This review provides an overview of the most common colorectal polyposis syndromes and inherited CRC syndromes, including adenomatous polyposis, hamartomatous polyposis, serrated polyposis, and those previously classified as non-polyposis CRC syndromes. The surveillance recommendations reported for each syndrome are applicable for probands with positive genetic testing or for those with high clinical suspicion for the syndrome who have refused genetic testing. Probands with negative genetic testing should be screened according to established guidelines for those with first-degree relatives with CRC.

Screening and surveillance recommendations are summarized in Table 3 at the end of the chapter.

Department of Surgery, Division of GI and General Surgery, Oregon Health \& Science University, Portland, OR, USA

Conflict of Interest: None

Correspondence to: Vassiliki Liana Tsikitis, MD, MCR, FACS, FASCRS, 3181 SW Sam Jackson Park Road, Mailcode L223A, Portland, OR 97239, USA, e-mail: tsikitis@ohsu.edu

Received 31 August 2017; accepted 30 October 2017; published online 27 November 2017

DOI: https://doi.org/10.20524/aog.2017.0218

\section{Familial adenomatous polyposis (FAP)}

\section{Epidemiology}

In northern European populations, FAP has an incidence between $1 / 13,000$ and $1 / 18,000$ live births [3]. It is the most common adenomatous polyposis syndrome, but is responsible for less than $1 \%$ of all CRC cases [4]. The likelihood of having cancer at the time of diagnosis of FAP increases with age, with one Swedish study showing a median age of diagnosis of 42 for patients with FAP who were found to have CRC at the time of diagnosis, 34 for patients with FAP but without CRC at diagnosis, and 22 for asymptomatic relatives of other FAP patients [5]. By the time patients with FAP are 40-50 years old, the risk of CRC approaches 100\% [6].

\section{Genetics}

FAP is caused by a mutation in the APC gene, found on chromosome 5q21 [7]. The mutation is inherited in an autosomal dominant fashion. The APC gene codes for a large tumor suppressor protein that affects cell adhesion and migration by regulating beta catenin as part of the Wnt-signaling pathway [3]. Most cases of sporadic CRC involve mutations in the APC gene as part of the adenoma-carcinoma sequence [7]. Many types and locations of $A P C$ mutations on the gene have been described in FAP. A genotype-phenotype correlation does exist, with mutations between codons 1250 and 1464 on the APC gene being associated with a severe form of FAP, and mutations at codon 1309 causing an especially severe form of the disease [4]. 
With standard genetic testing, $20-30 \%$ of patients with clinical FAP have no identifiable mutation in the APC gene [3]. One cross-sectional study demonstrated that the likelihood of identifying an $A P C$ mutation increased with the severity of the polyposis. In that study, an $A P C$ mutation was identified in $80 \%$ of patients with $>1000$ adenomas, $56 \%$ with $100-999$ adenomas, $10 \%$ with 20-99 adenomas, and 5\% with 10-19 adenomas [8]. With the development of more advanced genetic testing, such as monoallelic mutation analysis, APC mutation detection has greatly increased, with mutations identified in more than $95 \%$ of patients with clinical FAP [3].

\section{Presentation and diagnosis}

The diagnosis of FAP is based on the presence of 100 or more colorectal adenomas, or between 10 and 100 adenomas and a positive family history [7]. Between $30-40 \%$ of cases occur in the absence of a positive family history [4]. Adenomas most often develop in adolescence and are most commonly left-sided [3]. The most common presenting symptoms are gastrointestinal (GI) bleeding, diarrhea, abdominal pain, and mucoid discharge [7]. Approximately one quarter of patients will have CRC at the time of diagnosis [7].

FAP is also associated with multiple extracolonic manifestations. These include upper GI adenomas (present in $95 \%$ of cases), gastric fundic gland polyps (80-90\%), osteomas (80\%), congenital hypertrophy of retinal pigment epithelium (CHRPE) (75\%), epidermoid cysts (50\%), dental anomalies (17\%), desmoids (15-30\%), and adrenocortical adenomas (5\%). There are also associations with biliary tract cancers, papillary thyroid cancer, hepatoblastoma and medulloblastoma [7]. CHRPE is characterized by a patchy discoloration of the fundus of the eye [7].

Upper GI adenomas can be found in the stomach and throughout the small bowel, but occur most commonly in the duodenum, with $95 \%$ of patients having duodenal adenomas. Gastric adenomas are less common, occurring in $10 \%$ of patients. Gastric fundic gland polyps are very common and usually benign, although rarely can they progress to cancer. Given the very high prevalence of duodenal adenomas, it is not surprising that duodenal cancer is the second most common cause of death in FAP, after CRC [7]. Duodenal adenomas form later in life than colorectal adenomas, and the average age of an FAP patient at the time of duodenal cancer diagnosis is 50 years. They are most commonly peri-ampullary and develop around 15 years after colorectal adenomas. The duodenal adenoma burden is scored using the Spigelman staging system, which takes into account adenoma size, number, histology, and dysplasia (Table 1) [9]. The Spigelman score is used to determine the appropriate interval between upper endoscopies, which ranges from six months to five years (Table 2) $[9,10]$.

Desmoids are locally invasive tumors of mesenchymal origin, arising from myofibroblasts [11]. They most often occur in the absence of an underlying syndrome, but patients with FAP have an incidence of desmoids that is 850 times that of
Table 1 Spigelman scoring system for duodenal adenomas

\begin{tabular}{|c|c|c|c|}
\hline Variables & 1 point & 2 points & 3 points \\
\hline Number of polyps & $1-4$ & $5-20$ & $>20$ \\
\hline Polyp size (mm) & $1-4$ & $5-10$ & $>10$ \\
\hline Histology & Tubular & Tubulovillous & Villous \\
\hline Dysplasia & Mild & Moderate & Severe \\
\hline
\end{tabular}

Table 2 Recommendations based on Spigelman stage

\begin{tabular}{lcl}
\hline Spigelman score & Spigelman stage & Recommendation \\
\hline 0 & 0 & Re-scope in 5 years \\
$1-4$ & I & Re-scope in 3-5 years \\
$5-6$ & II & Re-scope in 3 years \\
$7-8$ & III & Re-scope in 1 year \\
$9-12$ & IV & $\begin{array}{l}\text { Consider } \\
\text { duodenectomy vs. } \\
\text { re-scope in } 6 \text { months }\end{array}$ \\
\hline
\end{tabular}

the general population [11]. They are most commonly found intra-abdominally and in the abdominal wall, representing the third most common cause of death in FAP, usually from bowel obstruction [7]. Known risk factors for the development of desmoids in FAP are female sex, prior surgery, and family history of desmoids [11].

\section{Cancer risk and surveillance}

CRC risk is essentially $100 \%$ by the time patients reach age 40-50 [3]. FAP patients are also at increased risk of duodenal, gastric, thyroid, and biliary tract cancers. Endoscopic screening of FAP patients and their family members has reduced the rate of $\mathrm{CRC}$ at the time of FAP diagnosis by $55 \%$ [3]. Screening has also increased their overall survival [3]. Screening recommendations differ slightly between American and European societies. The American Gastroenterological Association (AGA) recommends annual sigmoidoscopy for probands and their relatives, starting between ages 10-12 [3]. The European Society of Medical Oncologists (ESMO) recommends sigmoidoscopy every two years, starting between ages 12-14 [4]. Once adenomas are identified, annual colonoscopy is performed until prophylactic colectomy. Upper endoscopy with both front- and side-viewing scopes is also an essential part of screening and surveillance $[3,4]$. Upper endoscopy should begin once colorectal polyps are identified, or between ages 25-30, whichever comes first [4]. Once duodenal adenomas are identified, surveillance frequency and treatment are guided by the Spigelman staging system $[9,10]$. ESMO also recommends annual cervical ultrasound for thyroid cancer screening [4]. 


\section{Treatment}

The three surgical options for patients with FAP are total abdominal colectomy (TAC) with ileorectal anastomosis, total proctocolectomy (TPC) with ileal pouch anal anastomosis (IPAA), and TPC with end ileostomy. The timing of surgery depends on the severity of polyposis, the presence of dysplasia or malignancy, the presence of symptoms, and the intellectual and physical maturity of the patient, with most patients undergoing surgery between ages 15-25 [4,7]. Surgery should be performed as soon as possible in the presence of severe polyposis with $>1000$ adenomas or $>20$ rectal adenomas, in the symptomatic patient, and when high-grade dysplasia is present [7].

Full colonoscopy with biopsies is mandatory prior to surgical intervention. TAC with ileorectal anastomosis can be offered to young patients without severe polyposis, with a low rectal polyp burden (fewer than 5-10 rectal polyps), and without high-grade dysplasia [7]. There is a risk of developing cancer in the remaining rectum after TAC with ileorectal anastomosis. The cumulative risk of rectal cancer in patients with FAP after TAC with ileorectal anastomosis is estimated at $10 \%$ at 50 years of age and $29 \%$ at 60 years [3]. Although the risk of eventually developing rectal cancer is relatively high, one study showed that the mortality rate from rectal cancer after TAC and ileorectal anastomosis was only $2 \%$ after 15 -year follow up [12]. Because of the high rates of rectal polyp and rectal cancer development, postoperative surveillance endoscopy should be performed every six months to one year $[3,7]$. When rectal polyps are encountered, they should be removed endoscopically, if feasible. If rectal polyposis develops that is not endoscopically controllable, or if high-grade dysplasia is present, a completion proctectomy should be performed with either IPAA or end ileostomy [7].

Total proctocolectomy with IPAA involves removing the rectum and colon, and is thus preferred in cases of severe polyposis, for patients with significant rectal polyposis, and in the presence of high-grade dysplasia [7]. Previous teachings have advised proceeding straight to TPC rather than TAC in patients with a strong family history of desmoid disease, for fear it would make future completion proctectomy very difficult, if not impossible, to perform if eventually required. Recent data from a tertiary care center, however, has demonstrated that desmoid disease does not prevent the performance of completion proctectomy [13]. Studies have shown a lower incidence of duodenal adenomas after IPAA than after ileorectal anastomosis, possibly because alterations in the enterohepatic circulation cause decreased bile acid production. TPC with IPAA may therefore be the preferred initial surgical option for patients with a family history of significant duodenal polyposis [7]. TPC with IPAA is associated with a significant decrease in female fertility, compared with TAC and ileorectal anastomosis [3]. This should be discussed with women of child-bearing age prior to surgery, with one option being to proceed with TAC and ileorectal anastomosis initially, with plans to perform completion proctectomy and IPAA once child bearing is complete.

When performing TPC with IPAA, there is debate as to whether a stapled anastomosis or a mucosectomy and hand- sewn anastomosis is the best approach. The former requires leaving a 1-2 cm cuff of mucosa in the distal rectum and anal transition zone, while the latter removes as much mucosa as possible. Stapled IPAA anastomosis provides for significantly better functional outcomes, with less incontinence, seepage, and pad usage, but it also leads to a higher rate of polyps in the anal transition zone on postoperative endoscopic surveillance [14]. With either method, the risk of ileal pouch polyps is quite high after TPC with IPAA. The risk of ileal polyps is $7 \%$ at 5 years after surgery, $35 \%$ at 10 years, and $75 \%$ at 15 years [3]. Annual surveillance pouch endoscopy is recommended. TPC with IPAA is not a good option for patients with poor preexisting sphincter function, nor for those with advanced rectal cancer, and TPC with end ileostomy should be performed instead.

Treatment of desmoid disease is difficult, because of the very high rates of recurrence after surgery (up to 50\%) and their tendency to involve the root of the mesentery [7]. Surgery is often avoided in the case of intra-abdominal desmoids, unless the patient is symptomatic, usually from bowel obstruction or ischemia. Duodenal polyposis is often treated with frequent endoscopic surveillance and polypectomies, according to the Spigelman staging system. In the most severe cases (Spigelman stage IV), duodenectomy is indicated. This can be achieved with a pancreas-preserving total duodenectomy, which has been shown to have similar short-term morbidity and mortality to a Whipple procedure [15]. In the case of duodenal carcinoma, a Whipple procedure is indicated.

Although surgery is the mainstay of treatment for FAP, some medical treatments have been used for prevention of adenoma formation. Both sulindac, a non-steroid anti-inflammatory, and celecoxib, a cyclo-oxygenase- 2 inhibitor, have been shown to reduce the number and size of rectal polyps by inducing apoptosis, with a decrease in number as high as $72 \%$ [4]. Despite the significant decrease in size and number of polyps, no reduction in cancer risk has been shown [7].

\section{Attenuated FAP}

Attenuated FAP is characterized by fewer adenomas that develop later in life than do those in patients with FAP. It is defined as the presence of fewer than 100 adenomas. Adenomas usually develop in the fourth and fifth decades of life, with CRC developing in the sixth and seventh decades of life [4,7]. Like FAP, it is characterized by a germline mutation in the $A P C$ gene. Patients with attenuated FAP can have extracolonic manifestations, such as duodenal adenomas and fundic gland polyps, but do not have CHRPE [7]. Full colonoscopy is the appropriate screening tool, because adenomas can be localized to the right colon. ESMO guidelines recommend a colonoscopy every two years, starting between ages 18-20. Once adenomas are identified, colonoscopy should be performed annually [4]. Treatment for attenuated FAP is endoscopic polypectomy and annual colonoscopy if the polyp burden remains controllable endoscopically. If it does not, then TAC is warranted, with the same postoperative surveillance as in FAP [7]. 


\section{MutY homolog-associated polyposis (MAP)}

\section{Epidemiology}

MAP is a rare autosomal recessive adenomatous polyposis syndrome. Heterozygous carriers of the two most common mutations associated with MAP make up 1-2\% of the population in North America and Europe [2]. The median age of diagnosis is 48 [16].

\section{Genetics}

MAP is caused by biallelic mutations in the $M Y H$ gene. The inheritance pattern is autosomal recessive with high penetrance [4]. The MYH gene codes for a protein that repairs oxidative DNA damage. It does this by excising adenine base pairs that are misincorporated instead of cytosine [16]. Two missense mutations, Y179C and G396D, are by far the most common, and are present in up to $70 \%$ of patients with MAP [17]. Y179C is associated with a more severe phenotype [7]. Of all polyposis patients, biallelic MYH mutations were identified in $2 \%$ of patients with $>1000$ adenomas, $7 \%$ of patients with 100 999 adenomas, $7 \%$ of patients with $20-99$ adenomas, and $4 \%$ of those with 10-19 adenomas [18].

\section{Presentation and diagnosis}

Diagnosis is made with colonoscopy. Most patients have fewer than 100 adenomas, but some can have severe polyposis [4]. Polyps tend to be right-sided in MAP [7]. Patients are typically diagnosed in their 40 s and 50s, and the average age at CRC diagnosis is $50[4,16]$. Patients with MAP are at risk of extracolonic manifestations, including duodenal adenomas; the risk, however, is much lower than in FAP, with $<5 \%$ of MAP patients affected [17].

\section{Cancer risk and surveillance}

Biallelic MYH mutation carriers have an $80 \%$ risk of developing CRC by the time they are 70 years old [7]. While cancer most often develops in the setting of polyposis, up to one third of biallelic carriers develop CRC without an associated polyposis [4]. Monoallelic MYH mutation carriers also have an increased risk of developing CRC, with one study reporting a standardized incidence ratio of 2.12, comparable to that of a first-degree relative of a patient with sporadic CRC $[16,19]$. Although CRC risk is elevated in monoallelic carriers, CRC mortality, overall cancer risk, and overall mortality are not elevated in this group [16].

ESMO recommendations for surveillance for biallelic $M Y H$ carriers are colonoscopy every two years, starting between ages 18-20, in addition to esophagogastroduodenoscopy (EGD) starting between ages 25-30 [4]. Colonoscopy becomes annual once adenomas are found. For monoallelic
MYH mutation carriers, a screening regimen identical to that of a first-degree relative of a patient with sporadic CRC is recommended [4].

\section{Treatment}

Treatment strategies for MAP are similar to those for attenuated FAP. Endoscopic surveillance and polypectomy can be performed for as long as the polyp burden remains endoscopically controllable; a colectomy, however, is eventually required for most patients [4]. Annual surveillance endoscopy is recommended after surgery.

\section{Peutz-Jeghers syndrome (PJS)}

\section{Epidemiology}

PJS is a rare autosomal dominant syndrome associated with a hamartomatous polyposis throughout the GI tract. The syndrome confers an increased risk of a variety of cancers. Overall incidence of PJS is estimated at $1 / 200,000$ [7].

\section{Genetics}

PJS is caused by a mutation with autosomal dominant inheritance on a gene on chromosome 19 , known by two names, LKB1 and STK11. This gene is a tumor suppressor gene [20]. Between $80 \%$ and $94 \%$ of families with PJS phenotype have an identifiable LKB1/STK11 mutation [21,22].

\section{Presentation and diagnosis}

For patients without a family history of PJS, the World Health Organization (WHO) diagnostic criteria require three or more histologically-confirmed PJS polyps, or any number of histologically confirmed PJS polyps, and the characteristic mucocutaneous pigmentation. For patients with a family history of PJS, the WHO diagnostic criteria are any number of histologically confirmed PJS polyps, or the characteristic mucocutaneous pigmentation [23]. PJS polyps are hamartomas and are histologically described as a central core of smooth muscle that shows tree-like branching, covered by native mucosa heaped into folds, creating a villous pattern [24]. These polyps can develop anywhere throughout the GI tract, but are most common in the small bowel (78\%), stomach (38\%), colon (42\%), and rectum (28\%) [7]. The characteristic mucocutaneous pigmentation is a prominent melanin pigmentation in the perioral, peribuccal, and/or the genital regions. This pigmentation occurs in childhood, and typically fades when the patient is in his or her late 20s [7].

Presenting symptoms are most commonly related to anemia from chronic GI blood loss, as well as bowel obstruction [7]. 
Large PJS polyps can also act as a lead point and lead to an intussusception as an acute presentation [24].

\section{Cancer risk and surveillance}

The lifetime risk of cancer of any type in PJS is estimated to be $90 \%$. Patients with PJS develop an extensive variety of cancers, with 20\% developing CRC, 30\% breast, 30\% pancreas, $5 \%$ gastric, and others developing ovarian sexcord tumors, pulmonary cancers, and cervical cancers [7]. A prospective study by van Lier et al. spanning 14 years, has provided us with some robust data on cancer risk in PJS [24]. The cumulative risk for all cancers was $20 \%$ at age 40 and $76 \%$ at age 70 , with the risk for GI cancer being $12 \%$ and $51 \%$ at the respective ages. The median age at first cancer diagnosis was 45 . Cancer risk is significantly higher in women with PJS than in men with PJS, with a hazard ratio of 20.40 in women and 4.76 in men. This sex-related difference likely represents the high predisposition to breast and gynecologic cancers in the PJS population [24]. There was no difference between men and women in terms of GI cancer risk. Overall mortality was elevated in PJS patients compared to the general population, with a hazard ration of 3.50 and no statistically significant difference between sexes.

Surveillance recommendations for PJS are quite extensive, and reflect the wide variety of cancers that patients with PJS are predisposed to developing. Recommendations include yearly history and physical, capsule endoscopy every 2-3 years starting at age 10, EGD every 2-5 years starting at age 20, colonoscopy every 2-5 years starting between ages 25-30, magnetic resonance imaging (MRI) and/or endoscopic ultrasound of the pancreas every year starting at age 30, breast exam and breast MRI every year starting at age 25, mammography and breast MRI starting at age 30, pelvic exam, pap smear, transvaginal ultrasound, and CA-125 every year starting between ages 25-30 [24].

\section{Treatment}

Given the wide variety of cancers that patients with PJS may develop, surgical treatment is highly dependent on the type and location of the cancer. Colorectal polyps can usually be managed endoscopically, with polyps $>1.5 \mathrm{~cm}$ necessitating removal [7].

\section{Juvenile polyposis syndrome (JPS)}

\section{Epidemiology}

Juvenile polyps are hamartomas that lack smooth muscle [7]. They are the most common colorectal lesion in children. They are most commonly solitary and not associated with a syndrome or any malignant potential [7]. When they are part of JPS, however, they are associated with malignant potential and other anomalies. The overall incidence is $1 / 100,000$, and the average age at diagnosis is nine years [7].

\section{Genetics}

JPS has an autosomal dominant inheritance. Germline mutations in SMAD4 and BMPR1A have been implicated, with a mutation in either one identified in $39 \%$ of patients with the clinical syndrome [25]. Patients with SMAD4 mutations are more likely to have gastric polyposis and hereditary hemorrhagic telangiectasias [26].

\section{Presentation and diagnosis}

The diagnostic criteria for JPS are five or more colorectal juvenile polyps in the absence of a positive family history, any number of juvenile polyps with a positive family history, or multiple juvenile polyps in the upper and lower GI tract [7]. JPS always involves the colon, and the stomach and small bowel are each involved in $50 \%$ of cases [7]. Polyps most often develop by the third decade of life [27]. Between $10 \%$ and $20 \%$ of patients have associated congenital anomalies, such as macrocephaly, congenital heart disease, cleft lip and palate, genitourinary malformations, malrotation, telangiectasias, and GI and pulmonary arteriovenous malformations $[7,26]$. The most common presenting symptoms are rectal bleeding, anemia, and polyp prolapse [7].

\section{Cancer risk and surveillance}

The lifetime CRC risk for those with JPS is $39 \%$, while that for gastric cancer is $21 \%$ [26,27]. Mean age at the time of diagnosis of CRC is 44, and there is no difference in risk between men and women [27]. Recommended screening for first-degree relatives includes colonoscopy and EGD every 1-3 years, starting at age 12 , then switching to annual surveillance once polyps are found [28].

\section{Treatment}

Endoscopic surveillance and polypectomy is reasonable if the polyp load is controllable endoscopically. If the polyposis becomes uncontrollable, colectomy is required [7].

\section{PTEN hamartoma tumor syndrome (PHTS)}

\section{Epidemiology}

PHTS refers to multiple rare syndromes involving mutations in the PTEN gene, most notably Cowden syndrome 
Table 3 Surveillance recommendations

\begin{tabular}{|c|c|c|c|}
\hline Syndrome & Colorectal surveillance & Upper GI surveillance & Other cancer surveillance \\
\hline \multirow[t]{4}{*}{ FAP } & $\begin{array}{l}\text { Annual sigmoidoscopy starting at } \\
10-12 \mathrm{yo}^{1}\end{array}$ & $\begin{array}{l}\text { EGD with front and side-viewing scopes } \\
\text { starting when colorectal polyps are identified } \\
\text { or by } 25-30 \mathrm{yo}^{2} \\
\text { Interval determined by Spigelman stage (range } \\
\text { from q } 6 \text { mos to q } 5 \text { yrs) }\end{array}$ & Annual thyroid ultrasound ${ }^{2}$ \\
\hline & $\begin{array}{l}\text { q1-2 yr sigmoidoscopy starting at } \\
12-14 \mathrm{yo}^{2}\end{array}$ & & \\
\hline & $\begin{array}{l}\text { Switch to annual colonoscopy once } \\
\text { polyps are identified }\end{array}$ & & \\
\hline & $\begin{array}{l}\text { Annual endoscopy after TAC or } \\
\text { TPC IPAA }\end{array}$ & & \\
\hline \multirow[t]{2}{*}{ Attenuated FAP } & $\begin{array}{l}\text { Colonoscopy q2 yrs starting at } \\
18-20 \text { yo, then annual colonoscopy } \\
\text { once polyps identified }^{2}\end{array}$ & Same as FAP & None \\
\hline & $\begin{array}{l}\text { Annual endoscopy after TAC or } \\
\text { TPC IPAA }\end{array}$ & & \\
\hline \multirow[t]{2}{*}{ MAP } & $\begin{array}{l}\text { Colonoscopy q2 yrs starting at } \\
18-20 \text { yo, then annual colonoscopy } \\
\text { once polyps identified }^{2}\end{array}$ & Same as FAP & None \\
\hline & $\begin{array}{l}\text { Annual endoscopy after TAC or } \\
\text { TPC IPAA }\end{array}$ & & \\
\hline \multirow[t]{3}{*}{ PJS } & $\begin{array}{l}\text { Colonoscopy q2-5 yrs starting at } \\
25-30 \mathrm{yo}^{3}\end{array}$ & EGD q2-5 yrs starting at $20 \mathrm{yo}^{3}$ & $\begin{array}{l}\text { Breast: annual breast exam } \\
\text { and breast MRI starting at } 25 \\
\text { yo, add annual mammography } \\
\text { at } 30 \mathrm{yo}^{3}\end{array}$ \\
\hline & & Capsule endoscopy q 2-3 yrs starting at 10 yo $^{3}$ & $\begin{array}{l}\text { Pancreas: annual MRI and/or } \\
\text { EUS starting at } 30 \mathrm{yo}^{3}\end{array}$ \\
\hline & & & $\begin{array}{l}\text { GYN: annual pelvic exam, pap } \\
\text { smear, TVUS, CA- } 125 \text { starting } \\
\text { at } 25-30 \text { yo }^{3}\end{array}$ \\
\hline JPS & $\begin{array}{l}\text { Colonoscopy q1-3 yrs starting at } \\
12 \text { yo, switch to annual if polyps } \\
\text { found }^{4}\end{array}$ & $\begin{array}{l}\text { EGD q 1-3yrs starting at } 12 \text { yo, switch to } \\
\text { annual if polyps found }{ }^{4}\end{array}$ & None \\
\hline \multirow[t]{5}{*}{ PHTS } & $\begin{array}{l}\text { Colonoscopy at least q5 yrs } \\
\text { starting at } 35-40 \mathrm{yo}^{5}\end{array}$ & None & $\begin{array}{l}\text { Breast: annual mammography } \\
\text { and MRI starting at } 30 \mathrm{yo}^{5} \text {, } \\
\text { discuss prophylactic } \\
\text { mastectomies }\end{array}$ \\
\hline & & & $\begin{array}{l}\text { Thyroid: annual thyroid US } \\
\text { starting at the age of } d x^{5}\end{array}$ \\
\hline & & & $\begin{array}{l}\text { Kidney: renal imaging q1-2 yrs } \\
\text { starting at } 40 \mathrm{yo}^{5}\end{array}$ \\
\hline & & & $\begin{array}{l}\text { Endometrial: optional TVUS } \\
\text { and endometrial sampling }{ }^{5} \text {, } \\
\text { discuss prophylactic } \\
\text { hysterectomy }\end{array}$ \\
\hline & & & Skin: annual skin exam ${ }^{5}$ \\
\hline \multirow[t]{2}{*}{ SPS } & $\begin{array}{l}\text { Colonoscopy q } 5 \text { yrs of } 1^{\text {st }} \text {-degree } \\
\text { relatives starting at } 40 \text { yo or } 10 \mathrm{yrs} \\
\text { younger than the age of dx of SPS, } \\
\text { switch to annual if polyps found }{ }^{\neq 6}\end{array}$ & None & None \\
\hline & Annual endoscopy after colectomy & & \\
\hline
\end{tabular}


Table 3 (Continued)

\begin{tabular}{llll}
\hline Lynch & $\begin{array}{l}\text { Colonoscopy q1-2 yrs starting at } \\
20-25 \text { yo }^{2}\end{array}$ & None & $\begin{array}{l}\text { Gastric: Helicobacter pylori } \\
\text { testing and treatment }{ }^{2}\end{array}$ \\
& Annual endoscopy after colectomy & $\begin{array}{l}\text { GYN: annual pelvic exam, } \\
\text { pelvic US, endometrial } \\
\text { sampling, CA-125 starting at } \\
30-35 \text { yo }{ }^{2} \text {, prophylactic hyst/ } \\
\text { BSO for women }>40 \text { yo or } \\
\text { done with childbearing }\end{array}$ \\
Colorectal X & $\begin{array}{l}\text { Colonoscopy q3-5 yrs starting } \\
5-10 \text { yrs earlier than the youngest } \\
\text { age at CRC dx of family member }\end{array}$ & None & None \\
\hline
\end{tabular}

${ }^{1}$ American Gastroenterological Association, ${ }^{2}$ European Society of Medical Oncologists, ${ }^{3}[24],{ }^{4}$ American College of Gastroenterology, ${ }^{5}$ National Comprehensive Cancer Network, ${ }^{76}[37]^{7}$ US Multi-Society Task Force on Colorectal Cancer, ${ }^{8}[55]$

FAP, familial adenomatous polyposis; yo, years old; q, every; yr, year; TAC, total abdominal colectomy; TPC, total proctocolectomy; IPAA, ileal pouch-anal anastomosis; EGD, esophagogastroduodenoscopy; mos, months; MAP, mutY homolog-associated polyposis; PJS, Peutz-Jeghers syndrome; MRI, magnetic resonance imaging; EUS, endoscopic ultrasound; GYN, gynecologic; TVUS, transvaginal ultrasound; JPS, juvenile polyposis syndrome; PHTS, PTEN hamartoma tumor syndrome; $d x$, diagnosis; SPS, serrated polyposis syndrome; US, ultrasound; hyst/BSO, hysterectomy and bilateral salpingo-oophorectomy; Colorectal X, familial colorectal cancer X syndrome; CRC, colorectal cancer

and Bannayan-Riley-Ruvalcaba syndrome (BRRS). Cowden syndrome is more common in adults and women, while BRRS is most common in children and men [29].

\section{Genetics}

PHTS is characterized by germline mutations in the tumor suppressor gene, PTEN. This gene is located on chromosome $10 \mathrm{q} 23$ and plays an important role in inhibiting the mTOR and MAPK pathways [30-33]. PHTS is inherited in an autosomal dominant fashion and has $80 \%$ penetrance [33].

\section{Presentation and diagnosis}

PHTS has many associated anomalies, including macrocephaly, developmental delay, and autism. Macrocephaly is the most consistent, with $94 \%$ of patients having ahead circumference more than two standard deviations larger than normal [34]. Characteristic oral mucosal papillomatosis, as well as penile freckling are also associated with PHTS [29]. Most patients have thyroid disease, usually nodules or Hashimoto's thyroiditis, especially with Cowden syndrome. Trichilemommas, benign papular skin tumors, are pathognomonic for Cowden syndrome [7].

\section{Cancer risk and surveillance}

Tan et al.published the largest prospective study (368 patients) to examine cancer risks associated with PHTS [33]. The cumulative lifetime risk of breast cancer was $85 \%$, thyroid cancer was $35 \%$, endometrial cancer was $28 \%$, CRC was $9 \%$, kidney cancer was $34 \%$, and melanoma was $6 \%$ [33]. The cancer with the earliest average age of onset is thyroid cancer [29]. The vast majority (80-93\%) of PHTS patients who undergo colonoscopy have polyps. The most common type of colorectal polyp is hyperplastic, followed by hamartoma [29].

Screening recommendations from the National Comprehensive Cancer Networkinclude annual mammography and breast MRI starting at age 30, annual thyroid ultrasound from the age of diagnosis, optional transvaginal ultrasound and endometrial sampling, renal imaging every 1-2 years starting at age 40, colonoscopy at least every five years starting between ages 35-40, and annual skin examination [29]. Given that the breast cancer risk is similar to than in BRCA, prophylactic mastectomy is an option and should be discussed with the patient. Prophylactic hysterectomy is also an option, given the high risk of endometrial cancer [29]. Prophylactic oophorectomy is not necessary, as ovarian cancer risk is not elevated.

\section{Serrated polyposis syndrome (SPS)}

\section{Epidemiology}

SPS was formerly known as hyperplastic polyposis syndrome. Diagnosis usually occurs in the sixth and seventh decades of life [35-37]. Men and women appear to be affected equally [35,37].

\section{Genetics}

No specific germline mutation has been identified for SPS. The base excision repair genes MBD4 and $M Y H$ have been investigated in SPS with no significant association [38]. A family history of CRC is quite common in SPS, with large series reporting a positive family history in 38$50 \%$ of SPS patients [35,38]. The proposed mechanism of carcinogenesis in serrated polyps is hypermethylation causing inactivation of tumor suppressor genes. These 
tumors are commonly labeled CIMP (CpG island methylator phenotype) high [37].

\section{Presentation and diagnosis}

The diagnosis of SPS is defined by the WHO based on any one of the following criteria: 1) 20 or more serrated polyps anywhere in the colon; 2) 5 or more serrated polyps proximal to the sigmoid colon, with 2 polyps $>1 \mathrm{~cm}$; or 3 ) at least 1 serrated polyp proximal to the sigmoid colon and a firstdegree relative with SPS [39]. Symptoms are uncommon, and diagnosis is usually made during screening colonoscopy [26]. Sessile serrated polyps can be difficult to detect on colonoscopy as they are similar in color to the surrounding mucosa. Identification of the characteristic yellow or green mucus cap is helpful in identifying these lesions [37].

Kalady et al.have proposed at least three distinct clinical phenotypes within SPS. In their large series of 115 patients, they found $48 \%$ had relatively few large right-sided polyps, $16 \%$ had many small left-sided polyps, and $36 \%$ had a combination of left- and right-sided polyps. They found that the right-sided phenotype had an increased risk of CRC at a younger age [35].

\section{Cancer risk and surveillance}

A multicenter retrospective study of 77 patients with SPS found that $29 \%$ of patients had CRC at the time of their initial screening endoscopy. Five patients developed CRC during the study period, and the cumulative risk of CRC under surveillance was calculated to be $7 \%$ at five years [36]. An increasing number of serrated polyps was significantly associated with the development of cancer [36].

Once the diagnosis of SPS is made, annual colonoscopy should be performed. All serrated polyps should be removed if possible, or all polyps $\geq 5 \mathrm{~mm}$ should be removed if there are many diminutive polyps [37]. Due to the large proportion of SPS patients with a positive family history of CRC, screening colonoscopy is recommended for all firstdegree relatives of SPS patients starting at 40 years old or at 10 years younger than the age of diagnosis of SPS [37]. Full colonoscopy should then continue at 5-year intervals if no polyps are found [37].

\section{Treatment}

Annual colonoscopy with polypectomy can be performed as long as the polyp burden remains endoscopically controllable. When CRC develops, or when it is no longer feasible to control the polyp burden endoscopically, surgery is indicated. Surgical treatment most commonly consists of segmental oncologic resection of the cancer as well as segments with large polyps [37]. Annual endoscopic surveillance of the remaining rectum and colon is required postoperatively [37].

\section{Lynch syndrome}

\section{Epidemiology}

Lynch syndrome involves autosomal dominant mutations in mismatch repair (MMR) genes. It carries an increased CRC risk without an associated polyposis. It is the most common hereditary cancer syndrome, accounting for $1-3 \%$ of all CRC cases [4]. In addition to CRC, Lynch syndrome is also associated with a variety of other cancers.

\section{Genetics}

Lynch syndrome is characterized by autosomal dominant mutations in four different MMR genes: $M L H 1, M S H 2, M S H 6$, and PMS2 [4]. The incidences of the different mutations are quite different, with $M L H 1$ and $M S H 2$ mutations accounting for $80 \%$ of mutations, MSH6 making up $10-12 \%$, and PMS2 accounting for $2-3 \%$ [40]. There is an established genotypephenotype correlation: MLH1 mutations are associated with a higher risk of young-onset CRC, $M S H 2$ with a higher risk of extracolonic cancer, MSH6 with an increased risk of endometrial cancer, while PMS2 are associated with the lowest risk of CRC and endometrial cancer and later-onset cancers $[4,41]$.

\section{Presentation and diagnosis}

The Amsterdam criteria and Bethesda criteria are two diagnostic tools used to identify patients at risk for Lynch syndrome.

\section{Amsterdam II criteria}

1) Three or more relatives with a Lynch-associated cancer (CRC, endometrial, small bowel, genitourinary), with one being a first-degree relative of the other two

2) Two or more successive generations

3) One or more before the age of 50

4) Exclusion of FAP [42]

The revised Bethesda criteria state that a tumor should be tested for microsatellite instability (MSI) in any of the following circumstances:

1) $\mathrm{CRC}$ in a patient aged $<50$

2) Synchronous or metachronous CRC or other Lynchassociated tumors

3) CRC with high-level MSI histology in a patient aged $<60$

4) CRC in one or more first-degree relatives with a Lynchrelated tumor, with one of the cancers diagnosed at less than 50 years old

5) CRC in two or more first- or second-degree relatives with Lynch-related tumors [43]. 
While these two sets of criteria are helpful, their sensitivity in identifying patients with Lynch syndrome is low. The Bethesda guidelines have been shown to miss 6-25\% of patients with Lynch syndrome [44]. The gold standard for diagnostic testing is germline sequencing of the MMR genes. MMR sequencing of all CRCs in patients younger than age 70 should be performed, and universal testing for all CRCs, regardless of age, is the diagnostic approach that is most sensitive in identifying Lynch syndrome patients [45].

\section{Cancer risk and surveillance}

Lynch syndrome carriers have a lifetime CRC risk of 15-70\%; those with PMS2 mutations have the lowest risk $(15-20 \%)[40,41]$. There is also a significant lifetime risk of other Lynch-associated cancers. These include endometrial (30-60\% lifetime risk), genitourinary (8\%), ovarian (4-12\%), pancreatic (4\%), small bowel, gastric, biliary tract, brain, and skin cancers [46].

Frequent colonoscopic surveillance has been shown to decrease CRC incidence and CRC mortality [47]. ESMO guidelines recommend colonoscopy every 1-2 years, starting between ages 20-25. Endometrial cancer screening with annual pelvic exam, pelvic ultrasound, CA-125 and endometrial sampling, starting between ages $30-35$, is also recommended. ESMO also recommends testing for Helicobacter pylori, and treatment if positive, but does not recommend any screening for other Lynch-associated cancers [4].

\section{Treatment}

In the case of colon cancer in Lynch syndrome, TAC is the procedure of choice, rather than segmental colectomy, because of the superior risk reduction of metachronous CRC [45]. Multiple studies have demonstrated a drastic decrease in the risk of metachronous CRC in patients undergoing TAC compared to segmental resection, despite annual endoscopic surveillance [48-50]. One cohort analysis showed that the risk of developing a metachronous CRC after segmental colon resection is actually quite high: $16 \%$ at 10 years, $41 \%$ at 20 years, and $62 \%$ at age 30 [50]. Regardless of the choice of procedure (segmental colectomy vs. TAC), annual postoperative surveillance colonoscopy/endoscopy is recommended [45]. If a female patient with Lynch syndrome is over the age of 40 , finished with child-bearing, and/or undergoing colectomy, a prophylactic hysterectomy and salpingo-oophorectomy should be offered, according to the guidelines of the American Society of Colon and Rectal Surgeons [45]. This recommendation is based on a study comparing women with Lynch syndrome who underwent prophylactic hysterectomy and salpingooophorectomy and those who did not. None of the women in the prophylactic surgery group developed endometrial or ovarian cancer, while $33 \%$ of those who did not undergo surgery developed endometrial cancer and 5\% developed ovarian cancer [51].
In the case of rectal cancer in Lynch syndrome, treatment should be the same as for sporadic rectal cancer [45]. The risk of metachronous colon cancer after rectal cancer treatment is fairly high in Lynch syndrome, with one study reporting a rate of $15 \%$ at six years and another study reporting $27 \%$ after nine years [52,53]. Given the high risk of going on to develop metachronous colon cancer, it is reasonable to discuss a simultaneous prophylactic colectomy with the patient [45].

In addition to surgical treatment of Lynch syndrome, medical risk reduction of CRC can be achieved with aspirin. A randomized control trial demonstrated a $60 \%$ decrease in CRC incidence and other Lynch-associated cancers when patients took aspirin $600 \mathrm{mg}$ daily for at least two years [54].

\section{Familial CRC X syndrome}

This syndrome is represented by the $40 \%$ of families who meet Amsterdam I criteria, but have no identifiable MMR mutation [55]. These patients have an increased risk of CRC when compared to the general public, with a standardized incidence ratio of 2.3 , which is about one third of the standardized incidence ratio of people with Lynch syndrome [55]. Patients with familial CRC X syndrome do not show an increased incidence of the other Lynch-associated cancers [55]. Recommended surveillance is colonoscopy every 3-5 years, starting 5-10 years earlier than the age when the youngest family member was diagnosed with CRC [55]. CRC in patients with familial CRC X syndrome is treated identically to sporadic CRC.

\section{Concluding remarks}

Although each of the above syndromes is quite rare, it is important for clinicians to know the characteristics of each syndrome and to understand the differences in cancer risks between the different conditions. This information is very important when treatment and surveillance plans are formulated for each individual patient.

\section{Acknowledgment}

The authors would like to thank Mary Kwatkosky-Lawlor for her assistance with the review and submission process

\section{References}

1. Lichtenstein P, Holm NV, Verkasalo PK, et al. Environmental and heritable factors in the causation of cancer--analyses of cohorts of twins from Sweden, Denmark, and Finland. $N$ Engl $J$ Med 2000;343:78-85. 
2. Jones $\mathrm{N}$, Vogt $\mathrm{S}$, Nielsen $\mathrm{M}$, et al. Increased colorectal cancer incidence in obligate carriers of heterozygous mutations in MUTYH. Gastroenterology 2009;137:489-494, 494.e1.

3. Galiatsatos P, Foulkes WD. Familial adenomatous polyposis. Am J Gastroenterol 2006;101:385-398.

4. Balmaña J, Balaguer F, Cervantes A, Arnold D; ESMO Guidelines Working Group. Familial risk-colorectal cancer: ESMO Clinical Practice Guidelines. Ann Oncol 2013;24 Suppl 6:vi73-vi80.

5. Björk J, Akerbrant H, Iselius L, Alm T, Hultcrantz R. Epidemiology of familial adenomatous polyposis in Sweden: changes over time and differences in phenotype between males and females. Scand $J$ Gastroenterol 1999;34:1230-1235.

6. Vasen HF, Möslein G, Alonso A, et al. Guidelines for the clinical management of familial adenomatous polyposis (FAP). Gut 2008;57:704-713.

7. Apostolides, G. Hereditary polyposis syndromes. In: Cameron JL (editor): Current surgical therapy, C.A. Elsevier Saunders: Philadelphia; 2014, pp. 205-212.

8. Grover S, Kastrinos F, Steyerberg EW, et al. Prevalence and phenotypes of $A P C$ and MUTYH mutations in patients with multiple colorectal adenomas. JAMA 2012;308:485-492.

9. Spigelman AD, Williams CB, Talbot IC, Domizio P, Phillips RK. Upper gastrointestinal cancer in patients with familial adenomatous polyposis. Lancet 1989;2:783-785.

10. Brosens LA, Keller JJ, Offerhaus GJ, Goggins M, Giardiello FM. Prevention and management of duodenal polyps in familial adenomatous polyposis. Gut 2005;54:1034-1043.

11. Latchford AR, Sturt NJ, Neale K, Rogers PA, Phillips RK. A 10-year review of surgery for desmoid disease associated with familial adenomatous polyposis. Br J Surg 2006;93:1258-1264.

12. De Cosse JJ, Bülow S, Neale K, et al. Rectal cancer risk in patients treated for familial adenomatous polyposis. The Leeds Castle Polyposis Group. Br J Surg 1992;79:1372-1375.

13. Church JM, Xhaja X, Warrier SK, et al. Desmoid tumors do not prevent proctectomy following abdominal colectomy and ileorectal anastomosis in patients with familial adenomatous polyposis. Dis Colon Rectum 2014;57:343-347.

14. Remzi FH, Church JM, Bast J, et al. Mucosectomy vs. stapled ileal pouch-anal anastomosis in patients with familial adenomatous polyposis: functional outcome and neoplasia control. Dis Colon Rectum 2001;44:1590-1596.

15. de Castro SM, van Eijck CH, Rutten JP, et al. Pancreas-preserving total duodenectomy versus standard pancreatoduodenectomy for patients with familial adenomatous polyposis and polyps in the duodenum. Br J Surg 2008;95:1380-1386.

16. Sampson JR, Dolwani S, Jones S, et al. Autosomal recessive colorectal adenomatous polyposis due to inherited mutations of MYH. Lancet 2003;362:39-41.

17. Achatz MI, Porter CC, Brugières L, et al. Cancer screening recommendations and clinical management of inherited gastrointestinal cancer syndromes in childhood. Clin Cancer Res 2017;23:e107-e114.

18. Kastrinos F, Steyerberg EW, Mercado R, et al. The PREMM $(1,2,6)$ model predicts risk of $M L H 1, M S H 2$, and $M S H 6$ germline mutations based on cancer history. Gastroenterology 2011;140:73-81.

19. Win AK, Hopper JL, Jenkins MA. Association between monoallelic MUTYH mutation and colorectal cancer risk: a meta-regression analysis. Fam Cancer 2011;10:1-9.

20. Hezel AF, Bardeesy N. LKB1; linking cell structure and tumor suppression. Oncogene 2008.;27:6908-6919.

21. Volikos E, Robinson J, Aittomäki K, et al. LKB1 exonic and whole gene deletions are a common cause of Peutz-Jeghers syndrome. $J$ Med Genet 2006;43:e18.

22. Aretz S, Stienen D, Uhlhaas S, et al. High proportion of large genomic STK11 deletions in Peutz-Jeghers syndrome. Hum Mutat
2005;26:513-519.

23. Aaltonen LA, Jarvinen H, Gruber SB, et al. Peutz-Jeghers syndrome. In: Hamilton SR, Aaltonen LA (editors): World Health Organization Classification of Tumours. Pathology and Genetics. Tumours of the Digestive System. IARC Press: Lyon; 2000, pp. 74-77.

24. van Lier MG, Westerman AM, Wagner A, et al. High cancer risk and increased mortality in patients with Peutz-Jeghers syndrome. Gut 2011;60:141-147.

25. Howe JR, Sayed MG, Ahmed AF, et al. The prevalence of MADH4 and BMPR1A mutations in juvenile polyposis and absence of $B M P R 2, B M P R 1 B$, and $A C V R 1$ mutations. J Med Genet 2004;41:484-491.

26. Jasperson KW, Tuohy TM, Neklason DW, Burt RW. Hereditary and familial colon cancer. Gastroenterology 2010;138:2044-2058.

27. Brosens LA, van Hattem A, Hylind LM, et al. Risk of colorectal cancer in juvenile polyposis. Gut 2007;56:965-967.

28. Syngal S, Brand RE, Church JM, Giardiello FM, Hampel HL, Burt RW; American College of Gastroenterology. ACG clinical guideline: Genetic testing and management of hereditary gastrointestinal cancer syndromes. Am J Gastroenterol 2015;110:223-262; quiz 263.

29. Mester J. PTEN hamartoma tumor syndrome. In: Boardman L (editor) Intestinal polyposis syndromes. Springer: Switzerland; 2016, pp. 87-100.

30. Weng L, Brown J, Eng C. PTEN induces apoptosis and cell cycle arrest through phosphoinositol-3-kinase/Akt-dependent and -independent pathways. Hum Mol Genet 2001;10:237-242.

31. Stambolic V, Suzuki A, de la Pompa JL, et al. Negative regulation of $\mathrm{PKB} /$ Akt-dependent cell survival by the tumor suppressor PTEN. Cell 1998;95:29-39.

32. Gu J, Tamura M, Yamada KM. Tumor suppressor PTEN inhibits integrin- and growth factor-mediated mitogen-activated protein (MAP) kinase signaling pathways. J Cell Biol 1998;143:1375-1383.

33. Tan MH, Mester JL, Ngeow J, Rybicki LA, Orloff MS, Eng C. Lifetime cancer risks in individuals with germline PTEN mutations. Clin Cancer Res 2012;18:400-407.

34. Mester JL, Tilot AK, Rybicki LA, Frazier TW $2^{\text {nd }}$, Eng C. Analysis of prevalence and degree of macrocephaly in patients with germline PTEN mutations and of brain weight in PTEN knock-in murine model. Eur J Hum Genet 2011;19:763-768.

35. Kalady MF, Jarrar A, Leach B, et al. Defining phenotypes and cancer risk in hyperplastic polyposis syndrome. Dis Colon Rectum 2011;54:164-170.

36. Boparai KS, Mathus-Vliegen EM, Koornstra JJ, et al. Increased colorectal cancer risk during follow-up in patients with hyperplastic polyposis syndrome: a multicentre cohort study. Gut 2010;59:1094-1100.

37. Rex DK, Ahnen DJ, Baron JA, et al. Serrated lesions of the colorectum: review and recommendations from an expert panel. Am J Gastroenterol 2012;107:1315-1329.

38. Chow E, Lipton L, Lynch E, et al. Hyperplastic polyposis syndrome: phenotypic presentations and the role of MBD4 and $M Y H$. Gastroenterology 2006;131:30-39.

39. Snover D, A.D., Burt RW, Odze RD, Serrated polyps of the colon and rectum and serrated polyposis. In: Bosman CF, Hruban RH, Thieses ND (editors). WHO Classification of Tumours of the Digestive System. IARC Press: Lyon; 2000, pp. 160-165.

40. Lynch HT, de la Chapelle A. Hereditary colorectal cancer. N Engl J Med 2003;348:919-932.

41. Senter L, Clendenning M, Sotamaa K, et al. The clinical phenotype of Lynch syndrome due to germ-line PMS2 mutations. Gastroenterology 2008;135:419-428.

42. Vasen HF, Watson P, Mecklin JP, Lynch HT. New clinical criteria for hereditary nonpolyposis colorectal cancer (HNPCC, Lynch syndrome) proposed by the International Collaborative group on 
HNPCC. Gastroenterology 1999;116:1453-1456.

43. Umar A, Boland CR, Terdiman JP, et al. Revised Bethesda Guidelines for hereditary nonpolyposis colorectal cancer (Lynch syndrome) and microsatellite instability. J Natl Cancer Inst 2004;96:261-268.

44. Hampel H, Frankel WL, Martin E, et al. Screening for the Lynch syndrome (hereditary nonpolyposis colorectal cancer). $N$ Engl $J$ Med 2005;352:1851-1860.

45. Herzig DO, Buie WD, Weiser MR, et al. Clinical practice guidelines for the surgical treatment of patients with Lynch syndrome. Dis Colon Rectum 2017;60:137-143.

46. Win AK, Lindor NM, Winship I, et al. Risks of colorectal and other cancers after endometrial cancer for women with Lynch syndrome. J Natl Cancer Inst 2013;105:274-279.

47. Järvinen HJ, Aarnio M, Mustonen H, et al. Controlled 15-year trial on screening for colorectal cancer in families with hereditary nonpolyposis colorectal cancer. Gastroenterology 2000;118:829-834.

48. Kalady MF, McGannon E, Vogel JD, Manilich E, Fazio VW, Church JM. Risk of colorectal adenoma and carcinoma after colectomy for colorectal cancer in patients meeting Amsterdam criteria. Ann Surg 2010;252:507-511; discussion 511-3.

49. Natarajan N, Watson P, Silva-Lopez E, Lynch HT. Comparison of extended colectomy and limited resection in patients with Lynch syndrome. Dis Colon Rectum 2010;53:77-82.

50. Parry S, Win AK, Parry B, et al. Metachronous colorectal cancer risk for mismatch repair gene mutation carriers: the advantage of more extensive colon surgery. Gut 2011;60:950-957.

51. Schmeler KM, Lynch HT, Chen LM, et al. Prophylactic surgery to reduce the risk of gynecologic cancers in the Lynch syndrome. N Engl J Med 2006;354:261-269.

52. Kalady MF, Lipman J, McGannon E, Church JM. Risk of colonic neoplasia after proctectomy for rectal cancer in hereditary nonpolyposis colorectal cancer. Ann Surg 2012;255:1121-1125.

53. Win AK, Parry S, Parry B, et al. Risk of metachronous colon cancer following surgery for rectal cancer in mismatch repair gene mutation carriers. Ann Surg Oncol 2013;20:1829-1836.

54. Burn J, Gerdes AM, Macrae F, et al. CAPP2 Investigators. Longterm effect of aspirin on cancer risk in carriers of hereditary colorectal cancer: an analysis from the CAPP2 randomised controlled trial. Lancet 2011;378:2081-2087.

55. Lindor NM, Rabe K, Petersen GM, et al. Lower cancer incidence in Amsterdam-I criteria families without mismatch repair deficiency: familial colorectal cancer type X. JAMA 2005;293:1979-1985. 